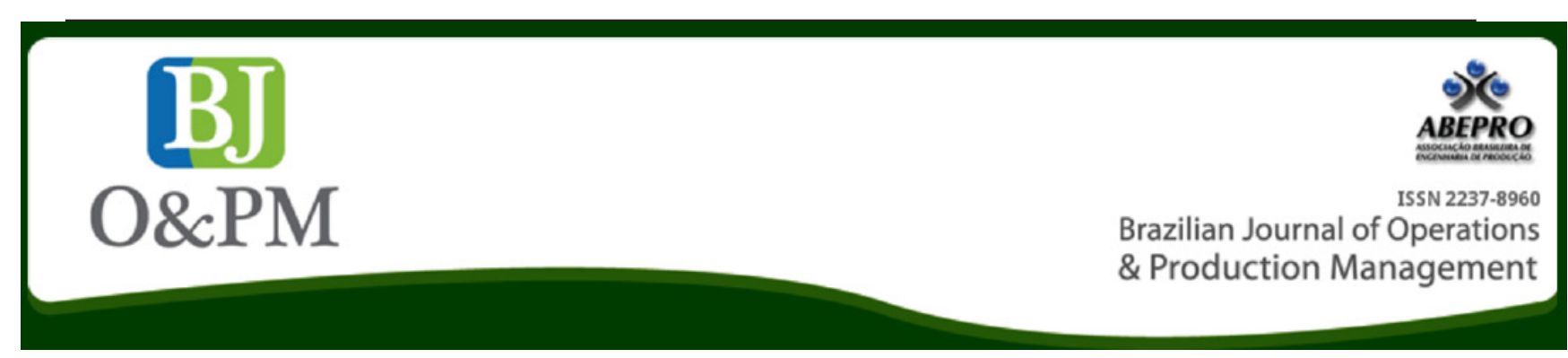

\title{
APPLYING LIFE CYCLE ASSESSMENT TO ANALYSE RESOURCE CONSUMPTIONS AND WASTE GENERATION IN A LABORATORY ANIMALS PRODUCTION
}

\author{
Ingrid Daré Vianaa, José Antonio Assunção Peixoto ${ }^{b}$, Leydervan de Souza Xavier ${ }^{b}$, Cristina Gomes de Souza ${ }^{b}$ \\ a Oswaldo Cruz Foundation/Institute of Science and Technology in Biomodels (FIOCRUZ/ICTB) - Rio de Janeiro, RJ, Brazil. \\ ${ }^{\mathrm{b}}$ Celso Suckow da Fonseca Federal Center for Technological Education (CEFET) - Rio de Janeiro, RJ, Brazil
}

\begin{abstract}
This study aims to quantify and analyze resource consumptions of a laboratory rabbits' production, in a Brazilian animal research facility, in order to produce a harmonized Health-Care Waste (HCW) classification, according to national regulations and international guidelines, as it is a basis to perform health and safety risk analysis, of animals, humans and environment impacts in HCW management. Methodologically, the principles and framework from Life Cycle Assessment were used to produce a doortodoor Life Cycle Inventory to produce the HCW classification and a short environmental impact assessment. A high electricity consumption (about 96\%), for conditioning facilities maintenance, and a high water consumption transformed into effluents and emissions (about 97.5\%) were observed. Specifically, from HCW classification a first analysis of mass pointed: effluents (45.92\%), emissions (52.54\%), biological waste (1.45\%) and common waste $(0.001$ $\%)$. These data are primary estimates that lead to deeper analysis of toxic materials and contamination. Finally, the entire study produced a cross fertilization of information giving more transparency about the rationality implied in the modeling of processes and presentation of reports, enabling to relate the local scope of impact assessment through broader reflections on global social responsibility and eco-efficiency.
\end{abstract}

Keywords: HCW management; Laboratory Animal; Animal Research Facilities; Health-care Waste; Life Cycle Assessment. 


\section{INTRODUCTION}

Currently, the management of laboratory animals productions (LAP), held in animal research facilities (ARF), must share international standards and guidelines to meet national regulations for conducting animal care and use programs aligned with Occupational Health and Safety programs (OHSP) of humans; everything aiming the integration of a complex combination of scientific parameters for modelling and production of animals. Thus, answering several demands of social responsibility and ecoefficiency control.

Internationally, one of the main references for ARF management is given by "The Guide for the Care and Use of Laboratory Animals, 8th.ed (the Guide) of the Institute for Laboratory Animal Research (2011). The Guide defines laboratory animals "as any vertebrate animal [...] produced for or used in research, testing, or teaching". Animal use it refers "as the proper care, use, and humane treatment of laboratory animals". Humane care means "those actions taken to ensure that laboratory animals are treated according to high ethical and scientific standards". In practice, humane care and use of animals imply the creation of an ethical and comfortable environment in the ARF and the implementation of programs in which human care and respect for animal are valued and encouraged, with OHSP focusing, simultaneously, the protection of animals, humans and ecology.

To develop a comprehensive animal care and use program, the Guide set, as a main directive, that Institutions must use the recommendations on "Three Rs principle" (3 Rs), proposed by Russell et Burch (1959), as strategic foundation for this development. Replacement refers to methods that avoid using animals making use of other technologies. Reduction refers to reduction of the number of animals used in experiments. Refinement refers to reduction of discomfort and improvement of the welfare of animals. Applying 3 Rs, investigators are strongly discouraged from advocating animal reuse as a reduction strategy, and the reduction should not be a rationale for reusing an animal (or animals) that have already undergone experimental procedures, especially if the welfare of the animals would be compromised in testing activities. A review of the literature, on alternatives to animals testing methods, can be found in Doke et Dhawale (2013) and Ranganatha et Kuppast (2012).

In the language of the Guide, to manage an animal care and use program requires, effectively, to establish policies and procedures, ensure regulatory compliance, monitor the program performance, support high-quality science and provide humane use of animals to reach a balance with the best chance of efficiently using resources while attaining the highest standards of animal well-being and scientific quality.
Simultaneously, as part of the effective management, each Institution must establish and maintain OHSP as an essential part of the "overall program of animal care and use". The publication (National Research Council 1997) informs that, in general, the responsibility for coordinating the OHSP, in research institutions, is often "delegated to the environmental health and safety staff" that extend the entire management scope to a wider conception of Environmental Health and Safety Program (EHSP) concerned with sustainable development.

In this context, the entire organizational effectiveness must be thinking as a complex interplay of engineering standards, performance standards and practice standards linked to global indicators of economic and socioenvironment concerns. This type of thought facilitates "to foster institutional compliance" among national regulations concerning occupational safety and health administration and the legislation and guidelines for environmental management.

Through EHSP, the emphasis has been placed on initiatives to developing, for instance, a local awareness of hazardous chemicals, chemical safety in laboratories, control of bloodborne pathogens, with the management of hazardous wastes being fundamental to the view and the deployment of performance indicators and impact identification, in different instances of operations, to aid studies on hazards, health, safety and risks.

In general, for operational purpose, best available techniques (BATs) are available without to disregard the highest ethical and scientific principles (The Guide; Bayne et Turner 2013, Hubrecht et Kirkwood 2010, Majerowicz 2008, Wolfensohn et Lloyd 2013). Mainly, they must be aligned with OHSP and must include specific concerns and procedures to accomplish Health-Care Waste (HCW) management, depending on types of local consumption, waste generation and waste classification and potential of consequences. But, although they are strongly focused on animal welfare and human and environment health and safety, they have been strongly related to a traditional quality management view and to maintain control of a number of risks of contamination, not always concerned with wider view of environmental protection.

As part of institutional OHSP, the waste generated in the ARF is, at least in a first instance, classified as HCW, which, according to the World Health Organization, is defined as "the total waste stream from a health-care facility", covering "all the waste generated by health-care establishments, research facilities, and laboratories" (WHO 2014). Nevertheless, according to Ananth et al.,(2010) and Komilis et al.,(2012), this designation can be changed. In Brazil, it is known as "Health Service Waste" (HSW) (ANVISA 2004). 
Particularly, in Brazil, HSW are regulated by the Collegiate Directory Resolution - RDC 306/2004 of the National Agency for Sanitary Vigilance -ANVISA (2004), and are also subject to Resolution 358/2005 of the National Environmental Council - CONAMA (2005) that provides more specific guidelines about treatment and final disposals.

In order to couple with the global governance, the Law 12,305/2010 (Brazil 2010) defined the National Solid Waste Police (PNRS) as the largest legal framework to solid waste management in the country. In this perspective, the framework is superposed to the previous regulation of ANVISA and CONAMA. The law is entirely focused on the eco-efficiency objective and have, as hierarchy to management: non-generation, reduction, reuse, recycle, and treatment of solid waste and suitable waste disposal. In addition, it recommends developing a shared responsibility through the life cycle of products as a way to develop sustainable partnerships based on economic and socioenvironmental responsibility. Hence, to engage in this regulatory environment, the initiatives of ARF sustainable management depend on harmonization of this point of view with those points of view concerning the use of the acronym 3Rs, among other conceptual demands. Thus, extending the OHSP approach to EHSP approach.

Concerned with the mapping of the life cycle of products, currently, worldwide, The United Nations recommends, through UNEP/SETAC (2015), that environmental management, of all types of organizations, should be compromised with the life cycle initiative (UNEP/SETAC 2013), beyond the local recommendations on solid waste management of UNEP (2005), and with additional regulation to produce a wider conciliation with the concept of social responsibility and eco-efficiency in the view of effectiveness. Nevertheless, the organizational integration of this conception remains a challenge, especially for developing countries (Soares et al.,(2013), as is the case of Brazil.

Within this scenery, this paper presents a study conducted in the ARF of a Brazilian science and technology health institution. The study was done with educational purpose, in order to explore the possibilities to accomplish quantifications of material consumption and a HSW classification and analyses aligned with the life cycle approach, as suggested by (UNEP/SETAC 2013) and PNRS.

So, the objective of this study was to quantify inputs and outputs of a laboratory rabbits' production, of a Brazilian Animal research facility, to identify the resource consumptions and to produce a health-care waste classification, according to Brazilian regulations, harmonized with international standards and guidelines supporting LCA.

\section{METHODOLOGY}

\subsection{Background}

According to UNEP (2005), in virtually all countries, the hierarchy to waste management is similar to:

- Prevent the production of waste, or reduce the amount generated;

- Reduce the toxicity or negative impacts of the waste that is generated;

- Reuse in their current forms the materials recovered from the waste stream;

- Recycle compost or recover materials for use as direct or indirect inputs to new products;

- Recover energy by incineration, anaerobic digestion, or similar processes;

- Reduce the volume of waste prior to disposal;

- Dispose of residual solid waste in an environmentally sound manner, generally in landfills.

It is supposed that the local waste management hierarchy must function as "a key element of integrated solid waste management" specifying "the precedence that should be given to key waste management activities that affect waste generation, treatment, and disposal" UNEP (2005). A very important point, in the integration of initiatives and official regulation, through the proposed hierarchy, is that behind them, in many developing countries, there is a tradition of solid waste management to be put into practice according to a prevalent terminology around a classical framework of waste prevention, reuse, and recycling (UNEP 2005). Sometimes, this implies to use a strategy not updated or well interpreted (or adjusted) in the application in course. In the case of the ARF management, it is necessary to clarify this sequence to prevent against misunderstandings or misleading actions, which, as have said before, discourage the searching of a better rationality when dealing with ethical issues and welfare of animals. Thus, confronting Russell et Burch 3Rs principles.

In this context, the main contribution of life cycle initiative would be to align quantification of inputs, outputs and waste classification, in the ARF, with many possibilities to conciliate 3Rs and PNRS hierarchy to prevent mistakes of rationality, as well as, to apply guidelines from the UNEP/SETAC (2013) and other similar contributions. In sum, it contributes to harmonize the rationale for interplay of assessment criteria and provide a way to transform organizational culture and the views of process toward sustainability (XAVIER et al., 2015). 


\subsection{Empirical context}

The empirical context of this study was the Laboratory Animal Production (LAP) of rabbits, which represent about $2.0 \%$ of the total animals supplied by the ARF, covering the last 6 years. This type of animal is widely used in biomedical research, in the stages of production and quality control, as well as in testing and education activities in the researches oriented to public health area.

Concerned as an exploratory study, the research included: process mapping; quantification of materials and waste, and the waste identifications and classifications.

\subsection{Process mapping}

The aim was to identify and plot the sequence of operations, activities and sub-processes (transitions) related to rabbit production, as well as the necessary connections among them. It was based on a survey of institutional documents, direct observation, and interviews with managers and technicians in charge of the LAP.

\subsection{Quantification of inputs and wastes}

To accomplish measurements of material consumptions and waste generations, taking into account both recommendations of PNRS and UNEP/SETAC (2013), a life cycle inventory $(\mathrm{LCl})$ was performed to cover a typical production of rabbits along three weeks. The methodological framework, for life cycle assessment (LCA), was proposed in ISO 14040 (ISO 2006a) and ISO 14044 (ISO 2006b) - in Brazil, NBR/ISO 14040:2009 and NBR/ISO 14044:2009.

\subsection{Waste Identification and Classification}

To support the waste identification and classification, it were used the instruction of RDC 306/2004 (ANVISA 2004) and Resolution 358/2005 (CONAMA 2005) frameworks.

\section{RESULTS AND DISCUSSIONS}

\subsection{Process Mapping}

The supply chain of laboratory animals production includes several stages from the extraction of raw materials to the final disposal of the waste. Some of these stages take place before the activities inside ARF and others afterward, as illustrated in supply chain represented in Figure 1.

The present study, however, was restricted to the LAP stage in the ARF. It begins with the receipt of raw materials and ends at the conclusion of the activities of the colony with the disposal of waste generated in the process.

The rabbit production sector is responsible for reproduction, growth and supply of animals to experimental purposes. The maintenance of this animal colony is held on a scheduled basis, to meet the anticipated demand of researchers.

The three animal rooms are divided in a way that, in two of them, there are the animals for reproduction, and, in the third, there are growing animals destined to experimental activities of researchers. The area selected to this study was the third one. However, as there was some operational support activities performed outside this room, their fluxes of linkage were also included.

The rabbit colony is kept under sanitary barriers, according to standardized environmental conditions, in order to contribute to the health and welfare of animals. The animals have no sanitary certification, being classified as conventional or holoxenical, what means that they have indefinite microbiota.

The rabbit production is composed of the following process transitions as shown in Fig 2. In T1, the technicians are submitted to body hygiene before entering the colony of rabbit room. T2 is a manual cleaning and disinfecting of all surfaces of the built area, to avoid or reduce the presence of microorganisms. T3 is a manual procedure performed by the

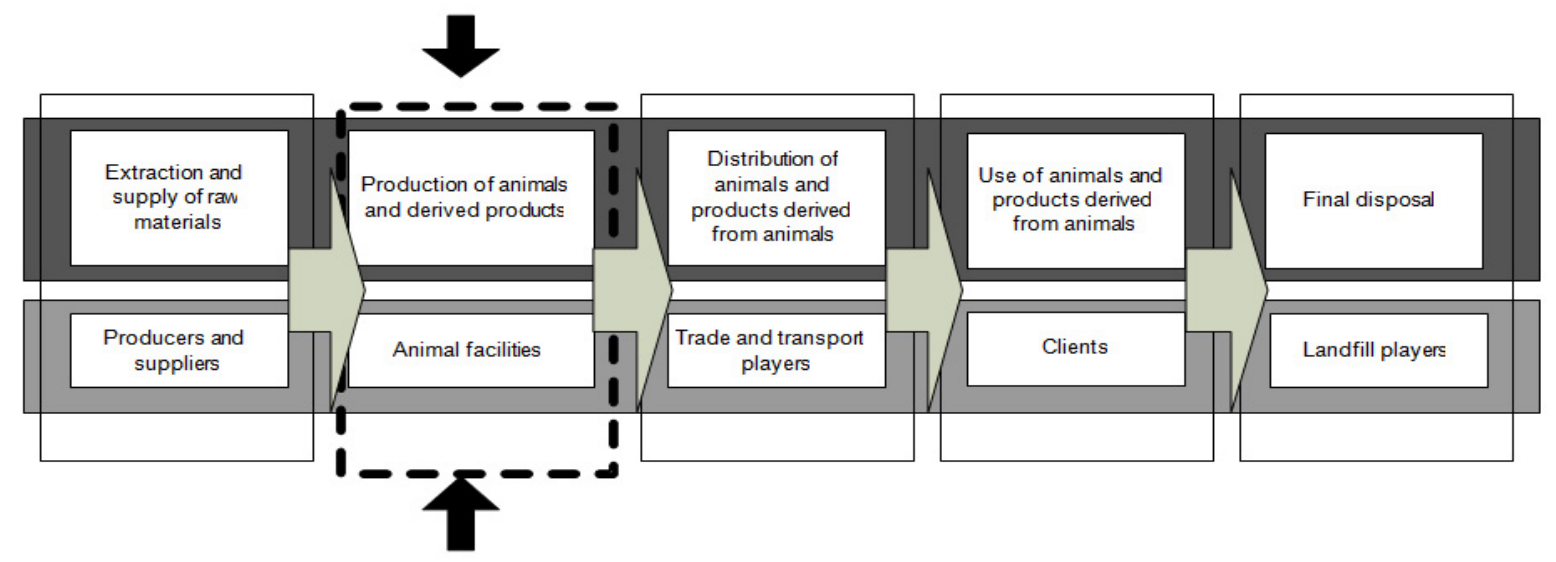

Figure 1. Supply chain of laboratory animals Source: The authors own 


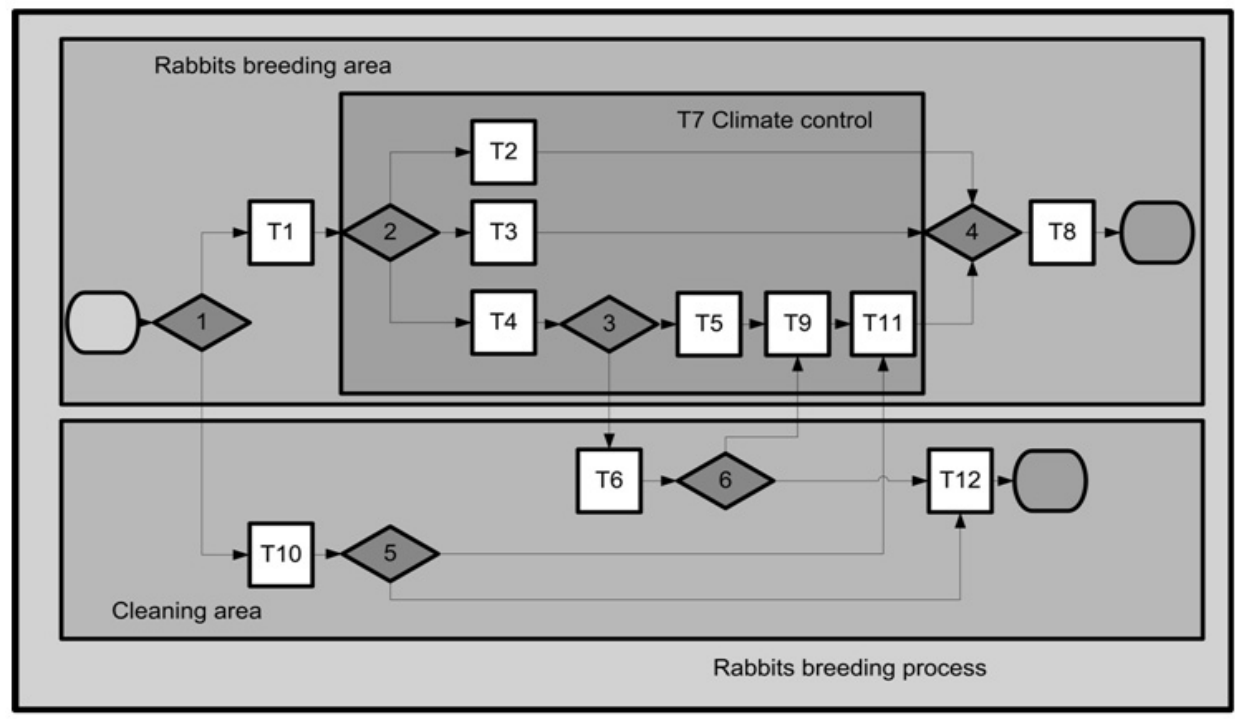

Legend: T1- entrance of sanitation; T2 - sanitation; T3 - colony maintenance; T4 - change of materials;

T5 - routine cleaning; T6 - cleaning of materials; T7 - environmental air conditioning; T8 - exit of sanitation;

T9 - disinfection; T10 - sterelization; T11 - storage; T12 - exit sanitation

Figure 2. Flowchart of rabbit production macro-process Source: The authors own

technicians of breeding that involves the supply of inputs, the evaluation of the animals, the activities of reproductive management and disposal of small part of colony waste.

T4 is a manual process performed by the technicians of breeding that involves replacing dirty materials racks by other sanitized, such as: trays, cages and accessories used by the animals over a week. T5 is the cleaning of the room floor, held after the exchange of materials. T6 is a cleaning of dirty materials after the workday end. T7 is a process to maintain appropriate environmental conditions to animal requirements. In T8, the breeding technicians are submitted to body hygiene, in the end of workday and after leaving the colony of rabbit room.

T9 is a manual procedure performed inside the airlock, consisting of direct application of aqueous solution of sodium hypochlorite on the surfaces of cages and trays being used by the colony. In this process there is no replacement of materials. In T10, it happens sterilization of inputs, such as wood shavings and hydrophobic cotton, ensuring their sanitary quality. Each sterilization cycle, performed in an autoclave of 4500 litres, consumes a total time of, at least, 80 minutes for the steps of pre-vacuum, sterilization, drying and cooling (about 20 minutes for each step). Currently, one cycle per week for shavings and one cycle every 15 days for cotton are performed, generating an average of 1.5 cycles per week for the room service. In T11, the materials - after cleaning and disinfection and those materials after sterilization- are kept in the room destined to storage and preparation of materials. This storage is inside the area of internal circulation, where the materials remain until utilization. In T12, the hygienization technicians are submitted to body hygiene, in the end of workday and after leaving the colony of rabbit room.

\subsection{Quantification of inputs and wastes}

In order to identify and quantify fluxes of resources and waste to compose the $\mathrm{LCl}$, a reduced approach of LCA was used supported by Umberto ${ }^{\circledR}$ software. The basis to monitoring was to perform measurements of the inputs and outputs flows of mass and electrical energy consumption. The system comprises the door-to-door boundaries of the ARF, according to the dashed line indicated in Figure 1 . The functional unit used was the typical production of rabbits along three weeks. The data collection for the $\mathrm{LCl}$ was performed, in loco, daily, including weekends.

The results of data processing and a presentation of $\mathrm{LCl}$ are shown in Figure 3. This information enables to check the amount of each input consumption and waste generation to link with several performance indicators.

The inputs and lighter waste generated during the field research were weighted with a precision balance situated in the colony. This equipment is normally used for weighing supplied items consumed by animals. The weighing of heavier waste materials, such as dirty litter, was done with a bigger balance installed in the area used for cleaning of the colony, which is normally used to weigh waste and materials such as cages and racks.

Some data were obtained from secondary sources, such as books, scientific articles and technical consultation 
to equipment manufacturers. The article "Airborne contaminants in conventional laboratory rabbit rooms" (Kaliste et al., 2002) was particularly useful for data related to greenhouse gas emissions generated in the animal production. A cooling system expert was also consulted.

The final values, presented for each input or waste output, were the averages of the values obtained in the assessment period.

In the case of the sanitation process, which is performed only once a month, it was adopted one proportional value. The data consistency was verified by mass balance and energy using the sheet model contained in Appendix A4 of the ISO 14044 (ISO 2006b).

The three animal rooms used in rabbit production are attended, during the week, by 3 employees. However, during weekend the service is done by 2 employees, working in on-duty system. So, it was observed that they entered and exited the production area 19 times. Each time, they took showers and used illumination facilities for personal hygiene. According to this description, the results related to the room studied corresponded to one third of the whole set of three rooms. The electrical energy consumed in baths and for illumination is related to personal hygiene and is, therefore, shared between Access Hygiene processes (entrance and exit).

The data computed in climate control were related to specific equipment installed in the room evaluated, so it does not include the consumption of the central chilled water cooling system that serves the entire facility. Similarly, in the stage of sanitizing materials, the steam consumption in local machines was recorded, but inputs and outputs relative to the steam production in the boiler unit, which supports the whole facility, were not computed. The processes were monitored and the inputs and outputs quantities were registered to accomplish the $\mathrm{LCl}$.

Comment: the entire LCA application is composed by other phases, nevertheless, in this work, the goal and scope of the $\mathrm{LCl}$ were defined to serve only as a simplified educational example of material consumption measurement and waste classification. The passages to a deep material consumption analysis, impact analysis and risk assessment (for instance through toxicological tests), as well as, the entire evaluation of LCA were not performed because these phases were out of the scope of this study.

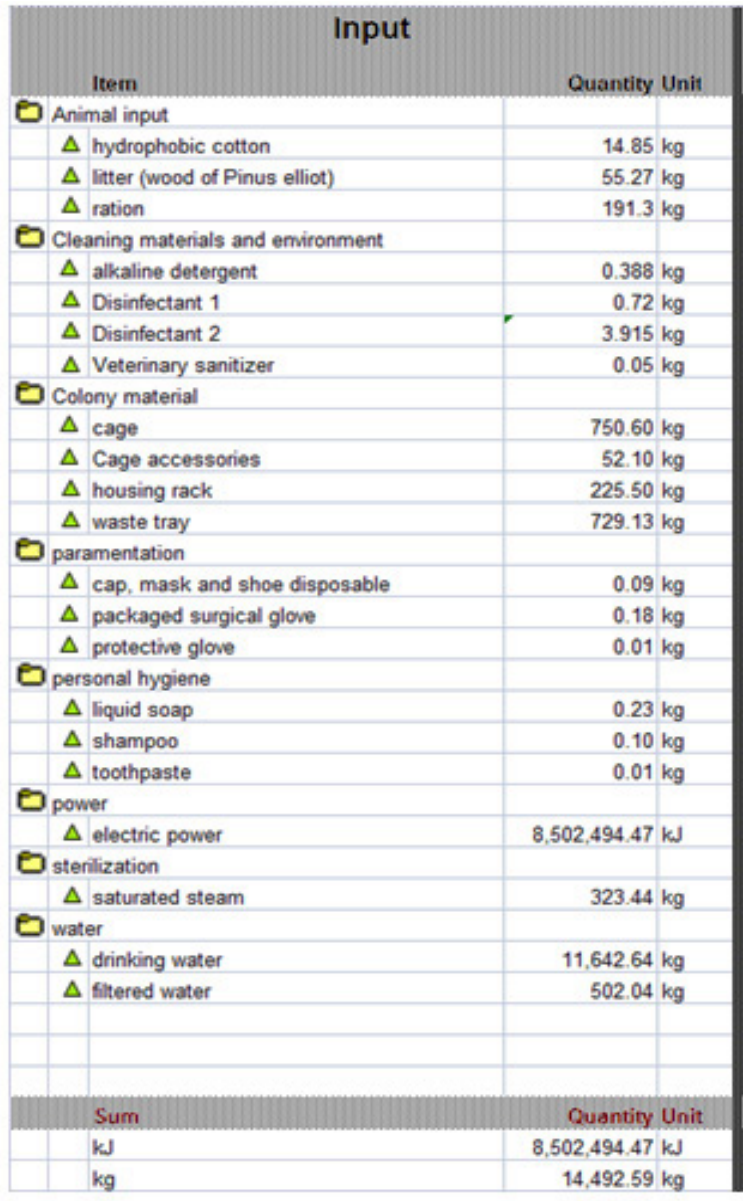

\begin{tabular}{|c|c|c|c|c|}
\hline & \multicolumn{2}{|r|}{ Output } & Quantity & Unit \\
\hline \multicolumn{3}{|c|}{ Animal input } & \multirow{2}{*}{\multicolumn{2}{|c|}{$7.5 \mathrm{~kg}$}} \\
\hline$\Delta$ & \multicolumn{2}{|c|}{ hydrophobic cotton } & & \\
\hline$\Delta$ & \multicolumn{2}{|c|}{ litter (wood of Pinus elliot) } & \multicolumn{2}{|c|}{$30 \mathrm{~kg}$} \\
\hline \multicolumn{5}{|c|}{ coefficient } \\
\hline$\Delta$ & \multicolumn{2}{|c|}{ coefficient generator of lagomorphs } & \multicolumn{2}{|c|}{$335.11 \mathrm{~kg}$} \\
\hline \multicolumn{5}{|c|}{ Colony material } \\
\hline$\Delta$ & \multicolumn{2}{|c|}{ cage } & 750.60 & $\mathrm{~kg}$ \\
\hline$\Delta$ & \multicolumn{2}{|c|}{ Cage accessories } & 52.10 & $\mathrm{~kg}$ \\
\hline$\Delta$ & \multicolumn{2}{|c|}{ housing rack } & 225.50 & $\mathrm{~kg}$ \\
\hline$\Delta$ & \multicolumn{2}{|c|}{ waste tray } & 729.13 & $3 \mathrm{~kg}$ \\
\hline \multicolumn{3}{|c|}{ paramentation } & & \\
\hline$\Delta$ & \multicolumn{2}{|r|}{ Disposable personal protective equipment used } & \multicolumn{2}{|c|}{$0.20 \mathrm{~kg}$} \\
\hline \multicolumn{3}{|c|}{ waste } & \multirow{3}{*}{\multicolumn{2}{|c|}{$3.93 \mathrm{~kg}$}} \\
\hline \multicolumn{3}{|c|}{ biological waste } & & \\
\hline & \multicolumn{2}{|c|}{$\boldsymbol{\Delta}$ animal carcass } & & \\
\hline & \multicolumn{2}{|c|}{$\Delta$ cage waste } & \multicolumn{2}{|c|}{$8.75 \mathrm{~kg}$} \\
\hline & \multicolumn{2}{|c|}{ dirty litter } & \multicolumn{2}{|c|}{$149.27 \mathrm{~kg}$} \\
\hline & $\Delta$ & residual ration & \multicolumn{2}{|c|}{$4.52 \mathrm{~kg}$} \\
\hline & $\boldsymbol{\Delta}$ & sweeping waste & 10.96 & $\mathrm{~kg}$ \\
\hline & $\Delta$ & waste retained in the washer machine & 2.58 & $\mathrm{~kg}$ \\
\hline & com & mon waste & & \\
\hline & $\Delta$ & cap, mask and shoe disposable used & 0.02 & $\mathrm{~kg}$ \\
\hline & $\Delta$ & Packaging glove & 0.04 & $\mathrm{~kg}$ \\
\hline & $\Delta$ & protective glove used & 0.01 & $\mathrm{~kg}$ \\
\hline 0 & efflue & & & \\
\hline & $\Delta$ & condensed sterilization & 876.64 & $\mathrm{~kg}$ \\
\hline & $\Delta$ & dirty water & 4605.97 & $\mathrm{~kg}$ \\
\hline & $\mathbf{\Delta}$ & residual water bottle & 199.16 & $\mathrm{~kg}$ \\
\hline 6 & emis & ssion & & \\
\hline & $\boldsymbol{\Delta}$ & ammonia & 0.40 & $\mathrm{~kg}$ \\
\hline & $\mathbf{\Delta}$ & dust / particles & 0.20 & $\mathrm{~kg}$ \\
\hline & $\Delta$ & water vapor & 6500.00 & $\mathrm{~kg}$ \\
\hline & & Sum & Quantity & Unit \\
\hline & & kg & $14,492.59$ & $\mathrm{~kg}$ \\
\hline & & & & \\
\hline
\end{tabular}

Figure 3. Rabbit Production Inventory Data Source: The authors own 
Brazilian Journal of Operations \& Production Management Volume 13, Número 4, 2016, pp. 472-481

DOI: 10.14488/BJOPM.2016.v13.n4.a7

\subsection{Waste Identification and Classification}

The identification and classification of waste were done according to RDC 306/2004 (ANVISA 2004) and CONAMA (2005). Both resolutions aim at HSW management, providing directives for treatment and final disposal of such waste. According to these resolutions, the HSW are classified into five groups: A (Biological), B (Chemical), C (Radioactive), D Common - similar to household and recyclable, and $E$ (Sharps and abrasive). Table 1 present the classification of waste generated by rabbit production.

Group A is composed of residues with the possible presence of biological

The waste classification facilitates a proper segregation and reduces health risks and handling expenses, thereby, generating the fractions, which will require safer and less costly actions for their treatment (Pilgerand et Schenato 2008).

\subsection{Quantitative analysis}

In relation to quantification of general consumptions, the most consumed inputs, among those required to create the animals, are: electricity, water, saturated steam, feed and shavings.

To illustrate, the data of consumption of energy, water and saturated steam, obtained from inventory and displayed in Figure 3 are rearranged in Table 2 and Figure 4 displays the distribution of electric power consumption and water waste and biological waste.

From Table 2, the energy demanded, weekly, by the room evaluated is $8,502,494.466 \mathrm{~kJ}$. This amount is consumed, mainly, to maintain the climatic conditions of the room, its lighting and air exchanges.

Figure $4 a$ shows that more significant consumption was of electric power (95.88\%), mainly to environmental air conditioning. Water consumption was also high, to maintaining air conditioning as well as cleaning. Drinking water was (95.87\%) and filtered water (4.13\%). Saturated stream was $323.42 \mathrm{Kg}$. The entire waste generated in rabbit production is represented in Figure $4 \mathrm{~b}$, by emissions (52.54\%), effluents (45.92\%), biological waste $(1.45 \%)$, and common residues $(0.01 \%)$. As it was illustrated, emissions are high due to the release of water vapour in the cooling system of the environment, which corresponds to $99.99 \%$ of this value.

The effluents, in Figure 4c, result from the high consumption of water, which is largely discarded after use, except for that consumed by animals.

The most representative among the biological waste, showed in Figure 4d, is the dirty shavings from the lining of trays that make up the system for rabbits housing.
The common waste represents only $0.01 \%$ of the total generated in the rabbit production, and it is composed by caps, masks, shoes, protective gloves and packaging gloves disposable.

\subsection{Waste analysis}

Among the existing classification groups of HSW, the production of rabbits generated waste of groups $A$ (represented by the residue class A4), B and D, with the exception of waste groups $\mathrm{C}$ (radioactive waste) and $\mathrm{E}$ (sharps).

The chemical residues (group B) identified are mainly represented by detergents and disinfectants used to clean and disinfect materials and environments.

These residues, although do not represent high hazard, may pose risks to workers and to environment, in case of improper handling and disposal. Workers can be affected by characteristics such as corrosivity, flammability and irritability; and there could be negative environmental impacts, if these residues were directly released into water bodies.

At ARF, these products are discarded during work process into local sewer pipes connected to internal effluent treatment unit of the Institution selected, where they are processed, prior to be released into public sewer system.

Among the waste classified as common (D), the recyclable materials must be highlighted, especially those from the natural wear of colony maintenance equipment such as cages and water dispensers, as they are subjected to constant processes of cleaning and sterilization in autoclaves at 121 으.

The biowaste, A4 class, represents most of the solid waste from the facility, and has lower potential risk than other classes of biological waste. Despite being classified by RDC306/2004 (ANVISA, 2004) as biological waste, a controversy surrounding this issue still persists. This is because this waste is produced by animals not infected/ inoculated and kept in controlled environments, under sanitary barriers. According to some researchers, the A4 residues could be compared to the sanitary waste or that from animals kept on farms, which are currently classified as ordinary waste. The Environmental Protection Agency (EPA 1994), for instance, only considers as medical waste, the following residues: animal contaminated carcasses, body parts, and bedding of animals, known to have been exposed to infectious agents during research, production of biological, or testing of pharmaceuticals.

The ARF performs disposal of waste A4 according to ANVISA (2004) procedures. Bags for infectious waste are used for packing and final disposal, at landfill, inside specific cells for this kind of residue. Carcasses of animals 


\begin{tabular}{|c|c|c|}
\hline Process & Waste & Classification \\
\hline \multirow[t]{2}{*}{ (T1) } & Personal hygiene products & $\mathrm{D}$ \\
\hline & Packaging of personal protective equipment & $\mathrm{D}$ \\
\hline \multirow[t]{3}{*}{$(\mathrm{T} 2)$} & Disinfectant benzalkonium chloride & B \\
\hline & Veterinary sanitizer with potassium monopersulfate & $\mathrm{B}$ \\
\hline & Protective glove & $\mathrm{D}$ \\
\hline \multirow[t]{4}{*}{ (T3) } & Animal Carcass & A4 \\
\hline & Sweeping waste the room & A4 \\
\hline & Packaging and dust of pelleted ration for rabbits & $\mathrm{D}$ \\
\hline & Veterinary medicine & B \\
\hline \multirow[t]{6}{*}{ (T4) } & Litter used to the bed with excreta & A4 \\
\hline & Hydrophobic cotton used to the nest with excreta and blood & A4 \\
\hline & Residual ration & A4 \\
\hline & Animal Carcass & A4 \\
\hline & Damaged cage and water bottle (polypropylene and polysulfone) & $\mathrm{D}$ \\
\hline & Sweeping waste the room & A4 \\
\hline \multirow[t]{2}{*}{ (T5) } & Disinfectant benzalkonium chloride & B \\
\hline & Disinfectant Sodium hypochlorite & B \\
\hline \multirow[t]{2}{*}{ (T6) } & Neutral and alkaline detergents & B \\
\hline & Filter water purifier & $\mathrm{D}$ \\
\hline (T7) & Hepa filter of the air conditioning system (ventilation and exhaust) & A4 \\
\hline \multirow[t]{3}{*}{ (T8) } & Personal hygiene products & $\mathrm{D}$ \\
\hline & Disposable surgical gloves & $\mathrm{D}$ \\
\hline & Personal protective equipment used (cap, mask and shoe) & $\mathrm{D}$ \\
\hline (T9) & Disinfectant Sodium hypochlorite & B \\
\hline \multirow[t]{3}{*}{ (T12) } & Personal hygiene products & $\mathrm{D}$ \\
\hline & Protective glove & $\mathrm{D}$ \\
\hline & Personal protective equipment used (cap, mask and shoe) & $\mathrm{D}$ \\
\hline
\end{tabular}

Source: The authors own

Table 2 - Consumption Process Data

\begin{tabular}{llll}
\hline Process & $\begin{array}{l}\text { Consumption } \\
\text { Energy }(\mathrm{kJ})\end{array}$ & $\begin{array}{l}\text { Consumption } \\
\text { Water }(\mathrm{kG})\end{array}$ & $\begin{array}{l}\text { Consumption Saturated } \\
\text { Steam }(\mathrm{kG})\end{array}$ \\
\hline T1 & $28,224.00$ & 361.00 & - \\
T2 & - & 8.28 & - \\
T3 & - & $393.69^{*}$ & - \\
T4 & - & $108.35^{*}$ & - \\
T5 & - & 67.23 & - \\
T6 & $220,670.47$ & $3,543.13$ & 46.80 \\
T7 & $8,152,416.00$ & $6,500.00$ & - \\
T8 & $28,224.00$ & 361.00 & - \\
T9 & $4,608.00$ & 112.00 & - \\
T10 & $40,320.00$ & 600.00 & 276.64 \\
T11 & $10,752.00$ & - & - \\
T12 & $17,280.00$ & 90.00 & - \\
Total & $\mathbf{8 , 5 0 2 , 4 9 4 . 4 7}$ & $\mathbf{1 2 1 4 4 . 6 8}$ & $\mathbf{3 2 3 . 4 2}$ \\
\hline
\end{tabular}

*Filtered water 


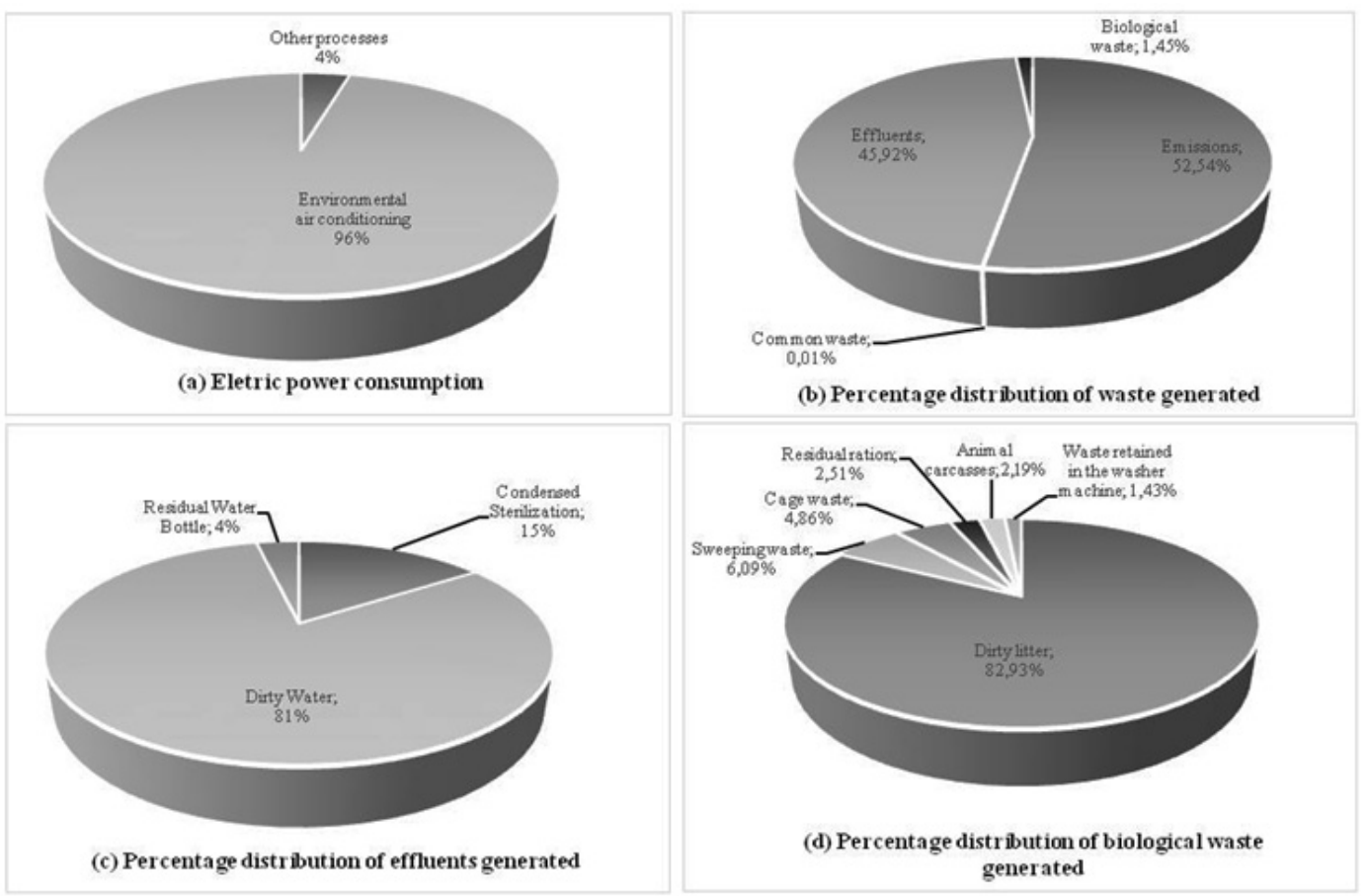

Figure 4. Distribution of electric power consumption and water waste and biological waste Source: The authors own

are destined for incineration. The transportation of waste is carried out by licensed company vehicles without garbage compactors. Another important factor is the compulsory use of special clothes by all employees handling this waste.

\section{CONCLUSIONS}

For the ARF perform their entire role, it is indispensable that LAP be according to all compulsory instance of regulation, and through the BATs, ever pursuing the 3Rs principles, for instance, according to the guide and the maintaining an appropriate HSW management. This procedure is essential to reducing risks to health, safety and environment, in the context of the entire institutional EHSP. To accomplish its objective, this study performed a process mapping of the laboratory rabbits' production processes, identifying and quantifying consumptions, to elaborating a $\mathrm{LCl}$. The process map and the $\mathrm{LCl}$ report became the basic information to align directives from Brazilian regulation with the international principles and framework for LCA, as well as, guidelines from UNEP/SETAC, in the ARF. In addition, the waste generated were identified and classified according ANVISA and CONAMA exemplifying a key effort, necessary to producing qualified information about material, energy, health-care waste, safety, hazards and risks, in order to share a path of social responsibility through the application of the concept of life cycle of products, as suggested by Brazilian PNRS.

Concerning HCW classification, three groups A, B and $D$, among five prescribed, were identified, what has demonstrated the diversity of the impact assessment and also clarified the need of monitoring and analysing the stages of handling and disposal of waste, as well as, of keeping employees permanently trained for safety.

The most consumed inputs at macro-process of rabbit production, according the $\mathrm{LCl}$, were electricity and water. Specifically, the processes with higher consumption of these resources are the Environmental climatization and Hygienization of materials.

The application of $\mathrm{LCA} / \mathrm{LCl}$ background, in the rabbit production process, gave an enhanced management perspective to the animal research facilities. This allows to perform analyses of different levels of eco-efficiency and socioenvironmental impacts and risks assessment, for instance, to proceed with toxicological analysis of residues and contamination, in a way that had not been experienced before.

Thus, our first suggestion is to analyse the possibilities to apply this proposal to other laboratory animal production, in order to consolidate a wider $\mathrm{LCl}$ and $\mathrm{HCW}$ classification as a basic support to the entire HCW management in the institution and, furthermore to diffuse LCA along all supply chains.

\section{ACKNOWLEDGEMENTS}

This work was partially supported by Foundation for Support of Research in the State of Rio de Janeiro (FAPERJ) and National Council for Scientific and Technological Development (CNPq). 


\section{REFERENCES}

Alves S. B.; Souza A. C. S.; Tipple A. F. V.; Rezende K. C.; de Resende F. R.; Rodrigues É. G.; Pereira M. S. (2014). The reality of waste management in primary health care units in Brazil. Waste Management \& Research 32: 40-47.

Ananth A. P.; Prashanthini V.; Visvanathan C. (2010) Healthcare waste management in Asia. Waste Management 30: 154-161.

ANVISA (2004) Collegiate Directory Resolution - RDC 306/2004 of the National Agency for Sanitary Vigilance. Brasília: Ministry of Heath.

Bayne, K.; Turner PV (2013). Laboratory Animal Welfare, San Diego: Elsevier.

Brazil (2008). Law 11,794/2008. From Presidency of Republic: http://www.planalto.gov.br/ccivil_03/_ato20072010/2008/lei/l11794.htm. (accessed June 19, 2014).

Brazil (2010). Law 12,305/2010. From Presidency of Republic: http://www.planalto.gov.br/ccivil_03/_ato20072010/2010/Decreto/D7404.htm. (accessed June 19, 2014).

CONAMA (2005). Resolution 358/2005 of the National Environmental Council, Brasília: Ministry of the Environment.

Doke SK; Dhawale SC (2015). Alternatives to animal testing: A review. Saudi Pharmaceutical Journal 23: 223-229.

EPA (1994). Guidance for evaluating medical waste treatment technologies, Washington, US: Environmental Protection Agency.

Haylamicheal ID, Dalvie MA, Yirsaw BD et Zegeye HA (2010). "Assessing the management of healthcare waste in Hawassa city, Ethiopia". Waste Management \& Research 1: $1-10$.

Hubrecht R et Kirkwood J (2010). The UFAW Handbook on the Care and Management of Laboratory and Other Research Animals, Oxford: Wiley-Blackwell.

Institute for Laboratory Animal Research (2011). Guide for the care and use of laboratory animals, $8^{\text {th }}$ ed., Washington, US: National Academic Press.

ISO (2006a). ISO 14040 - Environmental management Life cycle assessment - Principles and framework. Geneve: ISO.

ISO (2006b). ISO 14044 - Environmental management - Life cycle assessment - Requirements and guidelines. Geneve: ISO.

Kaliste E, Linnainmaa M, Meklin T et Nevalainen A (2002). "Airbone contaminants in conventional laboratory rabbit rooms". Laboratory Animals 36: 43-50.
Komilis D, Fouki A et Papadopoulos D (2012). "Hazardous medical waste generation rates of different categories of health-care facilities". Waste Management 32: 1434-1441.

Majerowicz J (2008). Boas Práticas em Biotérios e Biossegurança (Good Practices in vivarium and Biosafety), Rio de Janeiro: Editora Interciência.

National Research Council (1997). Occupational Health and Safety in the Care and Use of Research Animals, Committee on Occupational Safety and Health in Research Animal Facilities, Institute of LaboratoryAnimal Resources, Commission on Life Sciences. From The National Academies Press: http://www.nap.edu/catalog/4988.html (accessed October 25, 2015).

Ranganatha N et Kuppast IJ (2012). "A review on alternatives to animal testing methods in drug development". International Journal of Pharmacy and Pharmaceutical Sciences 4: 28-32.

Russell WMS et Burch RL (1959). The Principles of Humane Experimental Technique, London: Methuen and Co.

Soares SR, Finotti AR, Da Silva VP et Alvarenga RAF (2013). "Applications of life cycle assessment and cost analysis in health care waste management". Waste Management 33: 175-183.

Tesfahun E, Kumie A, Legesse W, et al. (2014). “Assessment of composition and generation rate of healthcare wastes in selected public and private hospitals of Ethiopia". Waste Management \& Research 32: 215-220.

UNEP (2005). Solid waste management. United Nations Environment Programme. From UNEP: http://www.unep. org/ietc/Portals/136/SWM-Vol1-Part1-Chapters1to3.pdf. (accessed August 27, 2015).

UNEP/SETAC (2013). Life Cycle Initiative. What is Life Cycle Thinking? From UNEP: http://www.lifecycleinitiative. org/starting-life-cycle-thinking/what-is-life-cycle-thinking/ (accessed February 17, 2013).

WHO - World Health Organization (2014) Safe Management of Wastes from Health-care Activities, 2nd ed, Geneve: WHO Press.

Wolfensohn S et Lloyd M (2013). Handbook of Laboratory Animal Management and Welfare, 4th ed, Oxford: WileyBlackwell.

Xavier L de S, Peixoto JAA, De Souza CG, Pontes AT et Futuro DO (2014). Life cycle thinking in graduate education: an experience from Brazil. International Journal of Life Cycle Assessment 19: 1433-1444. 